\title{
Prevalence of inflammatory bowel disease among coeliac disease patients in a Hungarian coeliac centre
}

Dorottya Kocsis ${ }^{1}$, Zsuzsanna Tóth ${ }^{2}$, Ágnes A. Csontos ${ }^{1}$, Pál Miheller ${ }^{1}$, Péter Pák ${ }^{3}$, László Herszényi ${ }^{1}$, Miklós Tóth ${ }^{1}$, Zsolt Tulassay ${ }^{1}$ and Márk Juhász ${ }^{7^{*}}$

\begin{abstract}
Background: Celiac disease, Crohn disease and ulcerative colitis are inflammatory disorders of the gastrointestinal tract with some common genetic, immunological and environmental factors involved in their pathogenesis. Several research shown that patients with celiac disease have increased risk of developing inflammatory bowel disease when compared with that of the general population. The aim of this study is to determine the prevalence of inflammatory bowel disease in our celiac patient cohort over a 15-year-long study period.
\end{abstract}

Methods: To diagnose celiac disease, serological tests were used, and duodenal biopsy samples were taken to determine the degree of mucosal injury. To set up the diagnosis of inflammatory bowel disease, clinical parameters, imaging techniques, colonoscopy histology were applied. DEXA for measuring bone mineral density was performed on every patient.

Results: In our material, 8/245 (3,2 \%) coeliac disease patients presented inflammatory bowel disease (four males, mean age 37, range 22-67), 6/8 Crohn's disease, and 2/8 ulcerative colitis. In 7/8 patients the diagnosis of coeliac disease was made first and inflammatory bowel disease was identified during follow-up. The average time period during the set-up of the two diagnosis was 10,7 years. Coeliac disease serology was positive in all cases. The distribution of histology results according to Marsh classification: 1/8 M1, 2/8 M2, 3/8 M3a, 2/8 M3b. The distribution according to the Montreal classification: 4/6 Crohn's disease patients are B1, 2/6 Crohn's disease patients are B2, 2/2 ulcerative colitis patients are S2. Normal bone mineral density was detected in $2 / 8$ case, osteopenia in $4 / 8$ and osteoporosis in 2/8 patients.

Conclusions: Within our cohort of patients with coeliac disease, inflammatory bowel disease was significantly more common $(3,2 \%)$ than in the general population.

Keywords: Coeliac disease, Inflammatory bowel disease, Crohn's disease, Ulcerative colitis

\section{Background}

According to the ESPGHAN definition, "Coeliac disease is an immune-mediated systemic disorder elicited by gluten and related prolamines in genetically susceptible individuals, characterised by the presence of a variable combination of gluten dependent clinical manifestations, coeliac disease specific antibodies, HLA-DQ2 and DQ8 haplotypes and enteropathy" [1]. However, coeliac disease $(\mathrm{CeD})$ may occur at any age, with the potential

\footnotetext{
* Correspondence: juhaszmarkdr@gmail.com

'2nd Department of Medicine, Semmelweis University, Szentkirályi st. 46., 1088 Budapest, Hungary

Full list of author information is available at the end of the article
}

involvement of any organs. The prevalence of $\mathrm{CeD}$ in Hungarian population ranges from 1 to $1,5 \%$ [2]. In adulthood, "classic symptoms" including diarrhea, abdominal distension, malabsorption syndrome are frequently absent. Patients may exhibit minor gastrointestinal complaints, as well as numerous extraintestinal manifestations. For the diagnosis of $\mathrm{CeD}$ in dietary naive adult patients serological and histological examination are necessary. After diagnosis, the basis of all the present treatments for $\mathrm{CeD}$ is the life-long gluten-free diet.

Nowadays, the range of diseases that can be proven to occur more frequently in untreated $\mathrm{CeD}$ has expanded. Various autoimmune diseases show association with 
$\mathrm{CeD}$, such as type- 1 diabetes mellitus, autoimmune thyroid disorders, selective IgA-deficiency, autoimmune hepatitis Sjögren's syndrome, juvenile chronic arthritis and the cutaneous form of celiac disease Dermatitis herpetiformis Duhring (DHD).

$\mathrm{CeD}$ and inflammatory bowel disease (IBD) are inflammatory disorders of the gastrointestinal tract with some common genetic, immunological and environmental factors involved in their pathogenesis. Several research showed that patients with $\mathrm{CeD}$ have a 5-10-fold risk of developing IBD when compared with that of the general population.

Fifteen years ago, an adult $\mathrm{CeD}$ centre was founded at Semmelweis University, 2nd Department of Internal Medicine, aiming to diagnose, care and follow-up $\mathrm{CeD}$ patients in a uniform manner. The number of treated adult patients has reached 300 by 2015, $50 \%$ from Budapest and $50 \%$ from the countryside. Thanks to the numerous presentations and publications on the activity of this adult $\mathrm{CeD}$ centre nationwide, this adult centre has gradually become a referral centre accepted and seeked by every gastroenterology outpatient settings in Hungary. Focusing on the closer region of our centre, the proportion of celiac patients ever recorded in this centre is estimated to be $30-40 \%$ of all adult celiac patients diagnosed and living in the central region of Hungary, with a total number of inhabitants of approximately 2.5 million people. Concerning IBD, the same department is one of the 11 centres of Hungary, having a state permission to provide IBD patients with biological therapy. The aim of this study was to establish the prevalence of IBD in our coeliac centre over a 15-yearlong study period.

\section{Methods}

Our study is a retrospective analysis. The data collection, processing and evaluating of the results were performed according to the existing legislation and in accordance with the Declaration of Helsinki. According to Hungarian guidelines no special ethical approval was required for this retrospective study.

Results of totally 248 patients with $\mathrm{CeD}$ attending the coeliac centre of 2nd Department of Medicine at Semmelweis University from November of 1997 till November of 2013 were analysed. There were $193 \mathrm{fe}-$ male and 55 male patients ( $78 \%$ vs. $22 \%$ ), with a mean age of 38 years, a median of 37 years and a range between 19 and 80 years. Of note, being a referral centre, in some cases, the diagnostic work-up of patients were launched in the primary care or at other settings. These patients were then referred to our centre for revision and confirmation of the suspected diagnosis. In order to diagnose $\mathrm{CeD}$, tissue transglutaminase antibody testing (tTG; IgA and IgG normal range: $0-10 \mathrm{U} / \mathrm{ml}$ ) and/or endomysium antibody tests (EMA) were used for serology. The IgG-tTG result was applied for cases of selective IgA-deficiency. Serological tests were carried out at Semmelweis University and the Coeliac Disease Center of Heim Pal Children's Hospital. Duodenal biopsy samples were taken to determine the degree of mucosal injury described according to the modified Marsh classification. Histological evaluation was performed mostly at the 1st Department of Pathology and Experimental Cancer Research of the Semmelweis University.

To set up the diagnosis of IBD, clinical parameters, imaging techniques, colonoscopy, video capsule endoscopy and histology were applied. Dual energy X-ray absorptiometry for measuring bone mineral density (BMD) was performed on every patient. Statistical analysis was

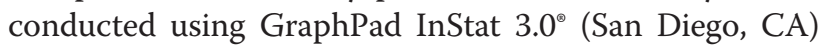
software.

\section{Results}

In our material, $8 / 245(3,2 \%) \mathrm{CeD}$ patients presented IBD. There were four males and four females, the mean age was 37 years, range 22-67 years. Crohn's disease (CD) was present in $6 / 8$ patients (three male, three female). Ulcerative colitis (UC) was present in $2 / 8$ patients (one male, one female). In 7/8 patients the diagnosis of $\mathrm{CeD}$ was made first and IBD was identified during follow-up. The average time period during the setup of the two diagnosis was 10,7 years (median: 5 years, range 4-535 months). All the eight patients with both IBD and $\mathrm{CeD}$ had serologic evidence of $\mathrm{CeD}$ at time of initial diagnosis. Serological tests were performed with tTG in 2/8 cases, and EMA in $6 / 8$ cases. The distribution of duodenal histology results according to MarshOberhuber classification were $1 / 8 \mathrm{M} 1,2 / 8 \mathrm{M} 2,3 / 8$ M3a, 2/8 M3b. The distribution according to the Montreal classification: 4/6 CD patients are B1 (nonstricturing, nonpenetrating) and $2 / 6$ patients are $\mathrm{B} 2$ (stricturing), 2/2 UC patients are S2 (moderate UC). Biological therapy (infliximab) was administered to 2/ 8 patients. One patient had selective IgA deficiency, and one patient also suffered from DHD. Osteodensitometry was performed on every patient with $\mathrm{CeD}$ and IBD. Normal BMD was detected in $2 / 8$ case $(1 / 2$ $\mathrm{CD}, 1 / 2 \mathrm{CU})$, osteopenia in $4 / 8$ patients $(2 / 4 \mathrm{CD}, 2 / 4$ $\mathrm{CU})$, and osteoporosis in $2 / 8$ patients $(2 / 2 \mathrm{CD})$. The mean body mass index (BMI) was $21,53 \mathrm{~kg} / \mathrm{m}^{2}$, range $17,28-23,94 \mathrm{~kg} / \mathrm{m}^{2}$. Mean BMI for males was 22,25 and $20,74 \mathrm{~kg} / \mathrm{m}^{2}$ for females, respectively (Table 1 ). All but one CeD-IBD patient had their $\mathrm{CeD}$ earlier diagnosed, than IBD; anemia was presented in totally four patients, diarrhea in two patients, loss of weight in two patients and one DHD in one patient, respectively. There was only $1 / 8$ patient whose IBD was earlier diagnosed, in his case serological screening aimed 
Table 1 Clinical characteristics of patients with inflammatory bowel disease and celiac disease

\begin{tabular}{|c|c|c|c|c|c|c|c|}
\hline Patients & Initial diagnosis & Second diagnosis & Time to second diagnosis & $\begin{array}{l}\text { Coeliac } \\
\text { serology }\end{array}$ & $\begin{array}{l}\text { Marsh- } \\
\text { classification }\end{array}$ & $\begin{array}{l}\text { Montreal- } \\
\text { classification }\end{array}$ & $\begin{array}{l}\text { BMD (bone mineral } \\
\text { density) }\end{array}$ \\
\hline 1 & Crohn's disease & Coeliac disease & $\sim 4$ month & $\mathrm{tTG}+$ & M2 & A2L3B1 & osteopenia. \\
\hline 2 & Coeliac disease & Ulcerative colitis & $\sim 9$ month & $\mathrm{tTG}+$ & M3a & A2E3S2 & osteopenia \\
\hline 3 & Coeliac disease & Crohn's disease & $\sim 8$ years (96 month) & EMA + & M3b & A2L3B2 & normal \\
\hline 4 & Coeliac disease & Crohn's disease & $\sim 20$ years (240 month) & EMA + & M1 & $\mathrm{A} 3 \mathrm{~L} 1 \mathrm{~B} 1$ & osteoporosis \\
\hline 5 & Coeliac disease & Crohn's disease & $\sim 5$ years 5 month (65 month) & EMA + & M3a & A2L2B2 & osteopenia \\
\hline 6 & Coeliac disease & Crohn's disease & $\sim 5$ years (60 month) & EMA + & $\mathrm{M} 2$ & $\mathrm{~A} 2 \mathrm{~L} 3 \mathrm{~B} 1$ & osteopenia \\
\hline 7 & Coeliac disease & Crohn's disease & $\sim 44$ years 7 month (535 month) & EMA + & M3b & A3L1B1 & osteoporosis \\
\hline 8 & Coeliac disease & Ulcerative colitis & $\sim 2$ years 1 month (25 month) & $\mathrm{EMA}+$ & M3a & A2E2S2 & normal \\
\hline
\end{tabular}

at several other autoimmune disorder resulted tTG positivity.

\section{Discussion}

Several autoimmune diseases are associated with CeD. To date, no conclusive evidence is available that proves if the relationship between $\mathrm{CeD}$ and autoimmune diseases is mediated by gluten exposure, or if $\mathrm{CeD}$ and autoimmune diseases could occur together due to other causes, particularly the injury of the integrity of the intestinal barrier function and the common genetic background (Table 1) [3]. Genetic studies have identified four shared risk chromosomal loci: PTPN2, IL18RAP, TAGAP, and PUS10 in both diseases [4]. This considerable overlap between the associated genetic regions might indicate partial agreement of the pathogenesis both of these diseases. Patients with IBD and CeD have number of common symptoms like diarrhea, malabsorption, weight loss, long-standing history of iron deficiency anaemia, and loss of BMD and this could cause problems in the diagnostics [5-7].

The prevalence of $\mathrm{CeD}(1: 100)$ multiply exceeds that of IBD (CD 0,1-16:10 ${ }^{4}$, UC 0,5-25:10 ${ }^{4}$ ) in general population [8]. Previous studies showed, that the prevalence of IBD is $5-10$ times higher in CeD compared with that of the general population [9-12].

In our cohort of patients with $\mathrm{CeD}$ the prevalence of IBD was $3,2 \%$. Other studies carried out among adult coeliac patients also found a similar prevalence of IBD. Yang et al. reported the prevalence of IBD to be $2,20 \%$ in a cohort of $455 \mathrm{CeD}$ patients [13]. Leeds at al. presented an IBD prevalence of 3,30\% among $305 \mathrm{CeD}$ patients, however the prevalence of $\mathrm{CeD}$ among IBD patients was comparable with that of the controls [14]. Furthermore, Casella et al. found lower risk of $\mathrm{CeD}$ in their cohort of IBD patients than in the general population [15]. Assumed cause of this difference is that the increased intestinal permeability in $\mathrm{CeD}$ may lead to increased antigen presentation and therefore generation of autoantibodies or increased bacterial translocation, which has been involved in IBD as a pathogenic mechanism $[14,16]$.

In our study, $\mathrm{CD}$ was more common than $\mathrm{UC}$ in a cohort of IBD patients. In contrast to our results, $\mathrm{CeD}$ were reported more frequently to be associated with UC than CD [10, 17-19]. Moreover, two further studies reported high prevalence of UC even among the firstdegree relatives of patients with $\mathrm{CeD}[20,21]$.

The average time period during the setup of the two diagnosis in our patients' cohort was 10,7 years, this result correspond well with the results from a previous study [13].

In our setting, in patients with both $\mathrm{CeD}$ and IBD, initial $\mathrm{CeD}$ serological testing were performed in most of the cases with EMA, which are highly specific for $\mathrm{CeD}$ and are not found in IBD [22]. tTG can be false positive in some chronic disorders such as type 1 diabetes mellitus and chronic liver diseases. Di Tola et al. and Farrace et al. both detected increased tTG IgA antibodies levels in patients with $C D$ and $U C[23,24]$. These results suggest positive tTG autoantibodies may be a phenomen of autoimmunity and loss of specificity in CeD [25].

At the time of the diagnosis, the majority of our patients the duodenal biopsies presented low stage (M1, M2, M3a) according to Marsh-Oberhuber classification. Histological findings of Marsh 1 were consider not fully sufficient for the diagnosis of $\mathrm{CeD}$, but the one of our patient, how presented M1 stage also had biopsy-proof Dermatitis herpetiformis Duhring, which is the skin manifestation of CeD. Casella and his colleagues observed similar distribution of histological results [15]. However, number of studies has found intraepithelial lymphocytosis and villous atrophy in CD patients without any evidence of $\mathrm{CeD}$ [26-28]. This histological status makes it difficult to differentiate CeD from CD.

In our patients' cohort, the dominant behaviour of IBD was of the inflammatory type, which is in line with data in literature $[14,15,29]$. 
In our study, the mean body mass index value of $21,53 \mathrm{~kg} / \mathrm{m}^{2}$ also falls within the normal range provided by the WHO. Unlike coeliac children, the vast majority of adult coeliacs are not malnourished, even overweight patients are not uncommon [30, 31]. However, malnutrition is a common feature of adult IBD [32]. In contrast to our results, low range of BMI in patients with both $\mathrm{CeD}$ and IBD has been reported [33-35].

IBD and $\mathrm{CeD}$ are associated with an increased risk of loss on BMD, caused by malabsorption and inflammation. Prevalence of osteoporosis were shown to be $7-35 \%$ in $\mathrm{CD}$ patients, $18 \%$ in UC patients, and $36-38 \%$ in untreated in $\mathrm{CeD}$ patients, respectively [36-40]. Interestingly, the loss of BMD in our patients with two different disease potentially leading to malabsorption syndrome were not worse than for those suffering in only one of these disorders.

\section{Conclusions}

In conclusion, within our cohort of patients with $\mathrm{CeD}, \mathrm{IBD}$ was significantly more common $(3,2 \%)$ than in the general population. On this basis celiac disease patients can be considered as a new potential inflammatory bowel disease risk group. Diagnosis of CeD mostly preceded the diagnosis of IBD. The dominant behaviour of IBD was of the inflammatory type. In our study, CD was more common than UC among patients suffering from CeD. The mean BMI value of our sample is within normal range. The loss of BMD for our patients with $\mathrm{CeD}$ and $\mathrm{CD}$ were not worse than for those suffering in only one of these disorders.

\section{Abbreviations}

BMD: Bone mineral density; BMl: Body mass index; CeD: Celiac disease; CD: Crohn disease; DEXA: Dual energy X-ray absorptiometry; EMA: Endomysium antibody; IBD: Inflammatory bowel disease; UC: Ulcerative colitis; tTG: Tissue transglutaminase antibody.

\section{Competing interests}

All the authors declare that they have no competing interests. The manuscript, including related data, figures and tables has not been previously published and that the manuscript is not under consideration elsewhere.

\section{Authors' contributions \\ DK carried out the studies and data analyses and performed the statistical analysis and drafted the manuscript. ZT and ÁAC participated in the design of the study. PM and LH carried out of the analyses of IBD patients samples. PP carried out the Video capsule endoscopy (VCE) analyses. MT carried out the bone mineral density analyses. MJ and ZTu conceived of the study, and participated in its design and coordination and helped to draft the manuscript. All authors read and approved the final manuscript.}

\section{Acknowledgements}

We would like to acknowledge the pathologist of Semmelweis University 1st Department of Pathology and Experimental Cancer Research the contribution by collecting data of histological samples.

\section{Author details}

'2nd Department of Medicine, Semmelweis University, Szentkirályi st. 46., 1088 Budapest, Hungary. ${ }^{2}$ Peterfy S. u. Hospital, Gastroenterology Unit, Péterfy S. st. 8-20., 1076 Budapest, Hungary. ${ }^{3}$ Vaszary Kolos. Hospital, Gastroenterology Unit, Petőfi S. st. 26-28., 2500 Esztergom, Hungary.

Received: 14 February 2015 Accepted: 8 October 2015

Published online: 19 October 2015

\section{References}

1. Husby S, Koletzko S, Korponay-Szabó IR, Mearin ML, Phillips A, Shamir R, et al. European Society for Pediatric Gastroenterology, Hepatology, and Nutrition guidelines for the diagnosis of coeliac disease. J Pediatr Gastroenterol Nutr. 2012;54(1):136-60.

2. Kocsis D, Miheller P, Lőrinczy K, Herszényi L, Tulassay Z, Rácz K, et al. Coeliac disease in a 15-year period of observation (1997 and 2011) in a Hungarian referral centre. Eur J Intern Med. 2013;24(5):461-7.

3. Diamanti A, Capriati T, Bizzarri C, Panetta F, Ferretti F, Ancinelli M, et al. Celiac disease and endocrine autoimmune disorders in children: an update. Expert Rev Clin Immunol. 2013;9(12):1289-301.

4. Festen EA, Goyette P, Green T, Boucher G, Beauchamp C, Trynka G, et al. A meta-analysis of genome-wide association scans identifies IL18RAP, PTPN2, TAGAP, and PUS10 as shared risk loci for Crohn's disease and celiac disease. PLoS Genet. 2011;7(1):e1001283.

5. Cronin CC, Shanahan F. Anemia in patients with chronic inflammatory bowel disease. Am J Gastroenterol. 2001;96(8):2296-8.

6. Annibale B, Severi C, Chistolini A, Antonelli G, Lahner E, Marcheggiano $A$, et al. Efficacy of gluten-free diet alone on recovery from iron deficiency anemia in adult celiac patients. Am J Gastroenterol. 2001;96(1):132-7.

7. Masachs M, Casellas F, Malagelada JR. Inflammatory bowel disease in celiac patients. Rev Esp Enferm Dig. 2007;99(8):446-50.

8. Lakatos PL. Recent trends in the epidemiology of inflammatory bowel diseases: up or down? World J Gastroenterol. 2006;12(38):6102-8.

9. Cooper BT, Holmes GK, Cooke WT. Coeliac disease and immunological disorders. Br Med J. 1978;1(6112):537-9.

10. Breen EG, Coghlan G, Connolly EC, Stevens FM, McCarthy CF. Increased association of ulcerative colitis and coeliac disease. Ir J Med Sci. 1987;156(4):120-1.

11. Kitis G, Holmes GK, Cooper BT, Thompson H, Allan RN. Association of coeliac disease and inflammatory bowel disease. Gut. 1980;21(7):636-41.

12. Delcò F, El-Serag HB, Sonnenberg A. Celiac sprue among US military veterans: associated disorders and clinical manifestations. Dig Dis Sci. 1999;44(5):966-72.

13. Yang A, Chen $Y$, Scherl E, Neugut Al, Bhagat G, Green PH. Inflammatory bowel disease in patients with celiac disease. Inflamm Bowel Dis. 2005;11(6):528-32.

14. Leeds JS, Höroldt BS, Sidhu R, Hopper AD, Robinson K, Toulson B, et al. Is there an association between coeliac disease and inflammatory bowel diseases? A study of relative prevalence in comparison with population controls. Scand J Gastroenterol. 2007;42(10):1214-20.

15. Casella G, D'Incà R, Oliva L, Daperno M, Saladino V, Zoli G, et al. Prevalence of celiac disease in inflammatory bowel diseases: an IG-IBD multicentre study. Dig Liver Dis. 2010;42(3):175-8.

16. Vermeire S, Noman M, Van Assche G, Baert F, Van Steen K, Esters N, et al. Autoimmunity associated with anti-tumor necrosis factor alpha treatment in Crohn's disease: a prospective cohort study. Gastroenterology. 2003;125(1):32-9.

17. Snook JA, de Silva HJ, Jewell DP. The association of autoimmune disorders with inflammatory bowel disease. Q J Med. 1989;72(269):835-40.

18. Casella G, Perego D, Baldini V, Monti C, Crippa S, Buda CA. A rare association between ulcerative colitis (UC), celiac disease (CD), membranous glomerulonephritis, leg venous thrombosis, and heterozygosity for factor $\mathrm{V}$ Leiden. J Gastroenterol. 2002;37(9):761-2.

19. Cheng SX, Raizner A, Phatak UP, Cho JH, Pashankar DS. Celiac disease in a child with ulcerative colitis: a possible genetic association. J Clin Gastroenterol. 2013;47(2):127-9.

20. Shah A, Mayberry JF, Williams G, Holt P, Loft DE, Rhodes J. Epidemiological survey of coeliac disease and inflammatory bowel disease in first-degree relatives of coeliac patients. Q J Med. 1990;74(275):283-8. 
21. Cottone M, Marrone C, Casà A, Oliva L, Orlando A, Calabrese E, et al. Familial occurrence of inflammatory bowel disease in celiac disease. Inflamm Bowel Dis. 2003;9(5):321-3.

22. Green PH, Jabri B. Coeliac disease. Lancet. 2003;362(9381):383-91.

23. Di Tola M, Sabbatella L, Anania MC, Viscido A, Caprilli R, Pica R, et al. Anti-tissue transglutaminase antibodies in inflammatory bowel disease: new evidence. Clin Chem Lab Med. 2004;42(10):1092-7.

24. Farrace MG, Picarelli A, Di Tola M, Sabbatella L, Marchione OP, Ippolito G, et al. Presence of anti-"tissue" transglutaminase antibodies in inflammatory intestinal diseases: an apoptosis-associated event? Cell Death Differ. 2001;8(7):767-70

25. Bizzaro N, Villalta D, Tonutti E, Doria A, Tampoia M, Bassetti D, et al. IgA and lgG tissue transglutaminase antibody prevalence and clinical significance in connective tissue diseases, inflammatory bowel disease, and primary biliary cirrhosis. Dig Dis Sci. 2003:48(12):2360-5.

26. Schuffler MD, Chaffee RG. Small intestinal biopsy in a patient with Crohn's disease of the duodenum. The spectrum of abnormal findings in the absence of granulomas. Gastroenterology. 1979;76(5 Pt 1):1009-14.

27. Wright $\mathrm{CL}$, Riddell RH. Histology of the stomach and duodenum in Crohn's disease. Am J Surg Pathol. 1998;22(4):383-90.

28. Culliford A, Markowitz D, Rotterdam H, Green PH. Scalloping of duodenal mucosa in Crohn's disease. Inflamm Bowel Dis. 2004;10(3):270-3.

29. Oxford EC, Nguyen DD, Sauk J, Korzenik JR, Yajnik V, Friedman S, et al. Impact of coexistent celiac disease on phenotype and natural history of inflammatory bowel diseases. Am J Gastroenterol. 2013;108(7):1123-9.

30. Dickey W, Bodkin S. Prospective study of body mass index in patients with coeliac disease. BMJ. 1998;317(7168):1290.

31. Nusier MK, Brodtkorb HK, Rein SE, Odeh A, Radaideh AM, Klungland H. Serological screening for celiac disease in schoolchildren in Jordan. Is height and weight affected when seropositive? Ital J Pediatr. 2010;36:16.

32. Mijac DD, Janković GL, Jorga J, Krstić MN. Nutritional status in patients with active inflammatory bowel disease: prevalence of malnutrition and methods for routine nutritional assessment. Eur J Intern Med. 2010;21(4):315-9.

33. Durusu M, Gürlek A, Simşek H, Balaban Y, Tatar G. Coincidence or causality: celiac and Crohn diseases in a case of Turner syndrome. Am J Med Sci. 2005;329(4):214-6.

34. Patel J, Agasti A, Rao S, Srinivas MG, Patel M, Sawant P. Celiac disease preceding Crohn's disease? Trop Gastroenterol. 2011;32(3):236-8.

35. Dickey W. A case of sequential development of celiac disease and ulcerative colitis. Nat Clin Pract Gastroenterol Hepatol. 2007;4(8):463-7.

36. Von Tirpitz C, Pischulti G, Klaus J, Rieber A, Brückel J, Böhm BO, et al Pathological bone density in chronic inflammatory bowel diseases - prevalence and risk factors. Z Gastroenterol. 1999;37(1):5-12.

37. Siffledeen JS, Fedorak RN, Siminoski K, Jen H, Vaudan E, Abraham N, et al. Bones and Crohn's: risk factors associated with low bone mineral density in patients with Crohn's disease. Inflamm Bowel Dis. 2004:10(3):220-8.

38. Keaveny AP, Freaney R, McKenna MJ, Masterson J, O'Donoghue DP. Bone remodeling indices and secondary hyperparathyroidism in celiac disease. Am J Gastroenterol. 1996;91(6):1226-31.

39. Duerksen DR, Leslie WD. Positive celiac disease serology and reduced bone mineral density in adult women. Can J Gastroenterol. 2010;24(2):103-7.

40. Bianchi ML. Inflammatory bowel diseases, celiac disease, and bone. Arch Biochem Biophys. 2010;503(1):54-65.

\section{Submit your next manuscript to BioMed Central and take full advantage of:}

- Convenient online submission

- Thorough peer review

- No space constraints or color figure charges

- Immediate publication on acceptance

- Inclusion in PubMed, CAS, Scopus and Google Scholar

- Research which is freely available for redistribution

Submit your manuscript at www.biomedcentral.com/submit 